\title{
Mathematical Modelling at Secondary School: the MACSI- Clongowes Wood College Experience
}

\author{
J.P.F. Charpin \\ MACSI, Department of Mathematics and Statistics, University of Limerick \\ S. O'Hara \\ Clongowes Wood College SJ, Clane, Ireland \\ Dana Mackey \\ Technological University Dublin, dana.mackey@tudublin.ie
}

Follow this and additional works at: https://arrow.tudublin.ie/scschmatart

Part of the Other Mathematics Commons

\section{Recommended Citation}

J. P.F. Charpin , S. O'Hara \& D. Mackey (2013): Mathematical modelling at secondary school: the MACSIClongowes Wood College experience, International Journal of Mathematical Education in Science and Technology, DOI:10.1080/0020739X.2012.756552

This Article is brought to you for free and open access by the School of Mathematics at ARROW@TU Dublin. It has been accepted for inclusion in Articles by an authorized administrator of ARROW@TU Dublin. For more information, please contact arrow.admin@tudublin.ie, aisling.coyne@tudublin.ie,gerard.connolly@tudublin.ie. Funder: Science Foundation Ireland/ MACSI

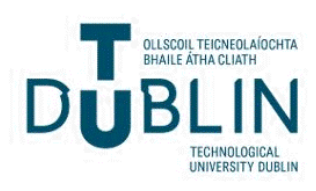




\title{
Mathematical Modelling at Secondary School: the MACSI-Clongowes Wood College experience J.P.F. Charpin ${ }^{1,2}$, S. O'Hara ${ }^{3}$ and D. Mackey ${ }^{4}$
}

\begin{abstract}
In Ireland, to encourage the study of STEM subjects and particularly mathematics, the Mathematics Applications Consortium for Science and Industry (MACSI) and Clongowes Wood College (County Kildare, Ireland) organised a mathematical modelling workshop for senior cycle secondary school students. Participants developed simple mathematical models for everyday life problems with an open-ended answer. The format and content of the workshop are described and feedback from both students and participating teachers is provided. For nearly all participants, this workshop was an enjoyable experience which showed mathematics and other STEM components in a very positive way.
\end{abstract}

\section{Keywords}

Mathematical modelling, secondary school, STEM, workshop content, feedback.

\footnotetext{
${ }^{1}$ Corresponding author. Email: jean.charpin@ul.ie

${ }^{2}$ MACSI, Department of Mathematics and Statistics, University of Limerick, Limerick, Ireland

${ }^{3}$ Clongowes Wood College SJ, Clane, Co. Kildare, Ireland

${ }^{4}$ School of Mathematical Sciences, Dublin Institute of Technology, Kevin Street, Dublin 8, Ireland
} 


\section{Introduction}

\subsection{The mathematics problem}

Mathematics is generally perceived as being dry and difficult. In particular, students at the beginning of their university degrees find the transition from secondary school extremely challenging and are under-prepared for the kind of mathematics they will face during their third level education. Researchers have documented this phenomenon, known as the 'mathematics problem' in numerous countries, for example, in the United Kingdom [1, 2, 3], Australia [4], Argentina [5] or the United States [4, 6]. These studies underline the progressive decline in the mathematical abilities of students and the unease of both lecturers and students at the level of mathematics in universities.

In Ireland, a review was carried out by Gill highlighting the specificities of the 'mathematics problem' in the country [7]. In particular, the points system controlling the entry into thirdlevel education and the changes in the mathematics syllabus at junior and leaving certificate level were pointed out: students do not concentrate on developing a genuine understanding of the mathematical concepts which they study. Instead, they focus on optimising their choice of question in the mathematics papers to maximise their exam mark [8]. To combat this trend, the new syllabus 'Project Maths' has been introduced progressively since September 2010. It aims to present students meaningful applications and develop their problem solving and analysis skills [9].

Workshops where students get the opportunity to apply the mathematics that they learn in class to real-world problems could facilitate the transition to third-level education and develop further understanding of mathematical concepts. They would put the mathematical topics studied in classroom into perspective: participants would be confronted with problems with which they are unfamiliar but using the mathematics they know, they would be perfectly capable of finding solutions for these real-life challenges. These workshops would also help to combat the bad image of mathematics.

\subsection{Importance of STEM}

The applications of mathematics are very strongly related to science, technology and engineering disciplines (forming all together the acronym STEM). The importance of these subjects has been underlined by reports all around the world [10, 11, 12]: STEM disciplines are absolutely necessary in industry, they also promote economical growth and the smart economy. However, these disciplines are not necessarily popular with the students and increasing the intake in these subjects is becoming more and more important.

In Ireland, numerous initiatives have been undertaken to make STEM disciplines popular. Science week, Engineering week and Maths week have been organised for several years to promote the disciplines among students and the wider public, create 'positive awareness' and orientate students towards degrees in the STEM area $[13,14,15]$. Similarly, the BT Young Scientist competition held in Dublin every year encourages students to work on STEM orientated projects and helps present these disciplines in the most positive fashion [16]. 
In academia, the Mathematics Application Consortium for Science and Industry (MACSI) organises a summer school every year during which 50 students, aged 16 to 18, are presented many different aspects and applications of mathematics [17]. During the summer school, one day is dedicated to participants producing models based on practical applications: the 'Mathematics in the real World' day. This session proves very popular with the students. Between October 2011 and April 2012, this was extended to a long term project in Clongowes Wood College, one of Ireland's leading boarding schools, located on the outskirts of Dublin. This project aimed to promote the idea of mathematical modelling and its connection with the other components of STEM. The different aspects of this project will be presented in this study.

\subsection{Paper outline}

The rest of this paper describes the background and organisation of this mathematical workshop. The elements needed for a successful project will be discussed. The workshop format is based on the study group with industry model. Study groups will be introduced in detail in Section 2 together with mathematical modelling teaching modules using a similar format. The workshop as it happened in Clongowes Wood College will then be presented in Section 3. Each stage of the process and their rationale will be discussed. To complete the study, some solutions developed by the students are detailed in Section 4 and students/teachers feedback is reported in Section 5.

\section{$2 \quad$ Study groups with industry and third level institutions}

Industry and University both play key parts in scientific research. Collaborations between industry and mathematicians can prove extremely successful and study groups with industry are an excellent example [18]. The study group format is used in university modules. These different embodiments are presented here as a prelude to the MACSI-Clongowes Wood College experiment. The organisation of study groups will be detailed first and teaching based on the study group format will then be described briefly.

\subsection{Study Groups with Industry}

Study groups with industry are typically week long intensive workshops involving mathematicians and industrialists/scientists who propose problems. These workshops are organised on a regular basis on all continents since they were created in Oxford in the 1960s. The study group format is standard:

- The first morning, industry representatives present the problems. They are usually not mathematical problems to begin with. Typically they are descriptions of a complicated industrial process which is not well understood from a scientific point of view. Usually, there is a specific question of the type 'How might we prevent this happening? 'Sometimes, the request is vaguer to the effect that if we can help to model the situation, 
something useful may come from the mathematical solutions. When all problems have been presented, the academic/scientific participants select the problem(s) they would like to work on.

- The first afternoon, subgroups of the scientific participants meet with each industry representative and ask far more detailed questions. Ideally, at the end of the day, the team should have defined in broad terms the approximate goals for the week.

- During the rest of the week, the group works on the problems and progresses towards a solution.

- On the last day, all groups present their results to the industry representatives and the other academics.

- A report describing the work of the group is written in the weeks following the study group and given to the industrial partner.

This format has proved extremely successful around the world and has been adapted for teaching purposes at university level as will now be described.

\subsection{Mathematical modelling: project based modules}

Two Mathematical Modelling modules are currently offered at Dublin Institute of Technology to first and second year students of the BSc in Mathematical Sciences degree. Each module consists of one two-hour lecture per week, is continuously assessed and is aimed at presenting applications of mathematics to real-world problems, while building teamwork and communication skills. This format is very close to the format used in study groups.

For each of these two courses, the class (20 to 50 students) is divided into groups, ideally of 5 students but ranging from 4 to 8 students. The groups are presented with a number of modelling problems throughout the year, which are to be worked on and completed within 2 to 3 weeks. The atmosphere of the modelling lectures is informal and students are free to discuss the problems with their teams, which often leads to heated arguments, or visit the library or computer lab.

A different group leader is nominated in each group for each of the problems. While the group as a whole is responsible for the preparation of all models, the group leader is responsible for coordinating the work of the group and the submission of the project. The group leader is also required to give an oral presentation based on the solution that the members of his/her team have prepared. Every student in the class gets a chance to be a team leader. Each group then receives a mark for each of the submitted projects, this accounts for $80 \%$ of the final mark. Additionally, each individual student receives a mark for the quality of the presentation of the project he was leader of which accounts for $20 \%$ of the grade.

The modelling projects are inspired by real world problems and, as such, they often lack sufficient data; it is up to the students to make appropriate assumptions. The students also discover that such problems are not 'textbook mathematics': there is no fixed method for solving them, there are many correct approaches and the problems are often open-ended. Because this 
'out of context' problem-solving approach is new to students (particularly in the first year of college), each project is usually developed in three phases:

1. Some new mathematical topic or technique is presented by the lecturer;

2. A 'practice' project is assigned, which usually lasts one lecture only and is concluded with discussions and possible solutions;

3. The final project is handed out.

Both the 'practice' and 'real' projects are related to the particular topic or technique discussed, although alternative solutions are always possible and, indeed, encouraged.

One of the topics presented to first year students was fitting sinusoidal functions to periodic data. After discussing the properties of the sine function, relating them to physical concepts such as frequency, amplitude, phase delay, and then working on a simple practice problem, the assessment project required building a sinusoidal model describing the phases of the moon. A potential starting point was to analyse data provided by online lunar calendars. This is not as simple as it seems: realising that the time between successive recurrences of the same phase varies from month to month is always guaranteed to lead to lively conversations! Other topics include standard mathematical concepts such as optimisation or exponential decay.

The end of the year feedback is generally positive with the vast majority of students describing the courses as 'fun and interesting' and reporting that they enjoyed learning about the practical applications of mathematics. Other positive comments refer to the experience of working in a group and having been allowed sufficient time to experiment with different ways of solving a problem. On the negative side, by far the most common complaint is related to the requirement for the oral presentation with more than half the students reporting that they dislike talking in front of the class and requesting a private presentation with the lecturer. Some students, however, do manage to overcome their (perceived) fear of public speaking and remark that 'it was easier than I thought' or 'it's a good skill to build'. Other difficulties reported include dealing with difference of opinions within the group and finding relevant material (i.e. books containing modelling case studies) in the library.

These modules taught in Dublin Institute of Technology show that the study group format can be used to teach mathematical modelling at university level. Adapting this format for secondary school students is possible and this will now be detailed.

\section{Workshop format and practical organisation}

35 male students attending Clongowes Wood College [19] volunteered to take part in this workshop. They were 15 to 18 year old and at the beginning of their senior secondary school cycle, called $4^{\text {th }}$ and $5^{\text {th }}$ year in Ireland, as detailed in Table 1.

\subsection{School's background}

Clongowes Wood College is one of Ireland's leading boarding schools drawing its 450 pupils (males only) from all over Ireland and abroad. Clongowes aims to create a community in which 
Table 1: Characteristics of students attending the workshop.

\begin{tabular}{cccc}
\hline Age/Year & $4^{\text {th } a}$ & $5^{\text {th } b}$ & Total \\
\hline 15 & 1 & 0 & $\mathbf{1}$ \\
16 & 11 & 3 & $\mathbf{1 4}$ \\
17 & 0 & 19 & $\mathbf{1 9}$ \\
18 & 0 & 1 & $\mathbf{1}$ \\
Total & $\mathbf{1 2}$ & $\mathbf{2 3}$ & $\mathbf{3 5}$ \\
\hline
\end{tabular}

${ }^{a}$ This is the first year of the senior secondary school cycle in Ireland.

${ }^{b}$ This is the second year of the senior secondary school cycle and second last year of secondary school in Ireland.

young people can develop the full range of their talents and abilities in a balanced, integrated and generous way. The aim is to educate each pupil to think and speak for himself, use his initiative, and provide leadership where required.

Each student studies science for four years with a specialist teacher for each of the three subjects, physics, chemistry and biology. The take up of science at senior cycle is very high with full classes in these three subjects. The College also has a very good record in both the Irish Physics Olympiad [20], with a student selected for the National team four out of the last six years, and in the Young Scientist Competition [16] .

\subsection{Rationale of the workshop}

The objective of the workshop is to give participants a first hand experience of mathematical modelling. They will gain this experience using a format close to the study group format. As is done in university modules, the industrial problems presented in study groups were replaced by simpler questions adapted to the age and scientific background of participants. The topics used in this first workshop were very successful and shared the following characteristics:

- They could be understood by everyone and referred to real life problems that would not be associated with mathematics in general.

- Many answers were possible.

- Workshop participants were not able to perform an experience reproducing the problem exactly.

- The descriptions lacked precision and left a lot of room for interpretation.

A set of problems that participants can easily relate to with these characteristics plays a vital role in the success of the workshop.

To develop their model, students went through the four key stages of mathematical modelling in general and study groups in particular. To start with, they had to understand the 
problem and analyse it carefully. Depending on the personal interests in the group and the difficulty of the task involved, students then decided which aspect of the problem they wanted to concentrate on for the duration of the project. They then drew up a plan outlining the different stages leading to a solution.

In the second stage, they gathered all the information they felt was necessary to produce a model. This data collection also allowed them to get a better understanding of the complexity of the problem and discovered the scientific and technical concepts they would need. Once they had all necessary data at their disposal, they were able to translate the plain English description of the problem into mathematical equations. Last but not least, they presented their results to a wider audience.

This experience could easily become overwhelming as students were not only faced with an unfamiliar approach but also with new concepts they were not necessarily familiar with. Participants therefore formed groups of 3 to 6 people. Working as a group minimised stress, encouraged emulation and favoured effective brainstorming and discussions. The qualities of group members were combined and individual contributions became elements of a result that participants would not be able to achieve on their own.

During the workshop as organised in Clongowes Wood College, two types of sessions alternated: plenary sessions during which general information was presented and homework sessions taking place outside of school hours under the supervision of the participants' Physics teacher which allowed them to make regular progress with their work. These different stages will now be described.

\subsection{First session: presentation of the projects and brainstorming.}

To start the workshop, a plenary session was organised with three objectives:

1. Explain to the students what is expected from them and how they will be able to achieve it.

2. Present the questions of which they are going to work.

3. Analyse the problem and decide what aspect(s) they want to concentrate their work on.

For this first workshop, a teacher from Clongowes Wood College and MACSI researchers were present in the room to assist and guide the participants. Participants could choose between three topics:

- If you were to run a marathon, how long would it take you?

- Who is popular? If you are member of social networks like Twitter or Facebook, how can you define who is the most popular person?

- Towing icebergs. Some countries where water is rare are considering towing icebergs from the poles to provide inhabitants with fresh water. Would this make sense? 
Table 2: Topics chosen by the participants

\begin{tabular}{lccc}
\hline Year & $4^{\text {th }}$ & $5^{\text {th }}$ & Total \\
\hline Marathon & 0 & 7 & $\mathbf{7}$ \\
Iceberg & 3 & 13 & $\mathbf{1 6}$ \\
Social networks & 9 & 3 & $\mathbf{1 2}$ \\
\hline
\end{tabular}

As shown in Table 2, all three topics were popular. The more sport orientated people in $5^{\text {th }}$ year chose the marathon topic. The remaining $5^{\text {th }}$ year mainly chose the iceberg problem while the fourth years mainly chose the social network question.

These three questions share the requested characteristics: participants were able to understand the problem straight away without lengthy explanations but were very quickly confronted to the complexity of the task. Numerous questions were raised by each of the problems, for example 'What is the physical condition of the runner?', 'What is the course of the marathon?', 'Is popularity limited by the number of friends?', 'How long do people spend on social networks?', 'How big is an iceberg?', 'How can you describe ice melting?'. After a few minutes of brainstorming, workshop participants realised, as they should have, that the problem was so wide ranging that they would not be able to treat of its aspects: a careful analysis became necessary. A full scale experiment was also impossible. To guide participants and give them a starting point for their discussion, three or four indications were provided: they referred to notions or methods that could be relevant to the problem. Participants were free to use or disregard them. Some guidance was also provided by their teacher and the MACSI people present at the session. At the end of this brainstorming session, the students had a clear idea of what they wanted to achieve and the tools they need to reach their goal.

\subsection{Homework: data gathering and analysis}

Once the group had decided the theme they wanted to work on, workshop participants had to look for the data they needed to develop their model. Students were working on real world problems: they therefore had to use realistic numbers for their models and also had to compare the results of their models with experimental data. This process was potentially extremely time consuming. This second stage was therefore performed during homework sessions.

A lot of information can be collected on numerous media. Three types are mainly of interest:

- Technical information. Participants were not necessarily familiar with every technical aspect of the problem: they could be unfamiliar with statistical tools or scientific concepts pointed out to them in the description of the problem. This type of information encouraged them to expand their scientific knowledge and showed them direct applications.

- Scientific information. When working on real life problems, realistic numbers should be used in the model. These could be as varied as physical or biological constants, economical facts or number of hits on a web page. Collecting this information familiarised participants 
with the notion of order of magnitude and underlined the importance of scientific reality checks.

- Experimental information. Parts of the problem might already have been considered in a variety of forms. There is no need to constantly 're-invent the wheel' and finding these resources could lead to substantial time gains.

Hardly any information being provided to the participants, they had to find their information from all the sources at their disposal. These included (non exhaustive list):

- Internet. Traditional search engines provide hundreds of sometimes contradicting answers to any question. Participants had then to use their own judgment to pick useful and relevant information.

- Library. Similar information may be found in books or journal articles. In some cases, workshop participants favoured this format.

- Own data collection. Depending on the nature of the answers, students could develop their own experiments to gather data. As the questions potentially involved any aspect of science, engineering or technology, the nature of the work performed was extremely varied. It took the form of a experiment in a scientific lab but could also be a survey among their peers for example.

- Teacher. Last but not least, their teacher provided extremely valuable guidance. Although this project focused on students working independently, the guidance of a teacher/ educator allowed participants to avoid many difficulties. This assistance took many forms ranging from an informal conversation to an impromptu lecture. This depended a lot on the personalities of the people involved.

Around 6 weeks of the project were devoted to this aspect of the work. The students collected information under the supervision of their teacher who helped them focus on their problem and made sure that the various information they collected remained relevant.

\subsection{Second and third sessions: formulating the model}

Formulating a model formed the centre of the workshop and was the newest aspect for participants. Using the data they had collected, they had to translate the problem expressed in plain English into mathematics formulas. A complete plenary session was devoted to assist participants with the production of a first basic model. A simple example was presented illustrating how they should proceed. However, no general method can be devised to produce a successful model. Instead some general guidelines were presented:

- Multiple answers. Due to the nature of the questions, many answers were acceptable. They were not necessarily contradictory as the problem could be tackled from many angles. A good example to illustrate this difficulty is the comparison of university ranking methods, see for example $[21,22,23]$. Each of these ranking systems reflects different 
qualities of the universities considered but they all lead to different orders. It does not make any of them better or worse than the other. They all just highlight different aspects of these institutions. Similarly, the problems considered in this workshop lead to very different answers.

- Simplicity. A significant difficulty faced by workshop participants was the complexity of real world problems as they could attempt to include too many parameters in their model. In this case, they were likely lose sight of the real goals and they risked not being able to find an answer. A key element to success was therefore simplicity. For each problem, a few leading parameters arose from the data collection. In their first model prototype, the participants favoured simplicity and mainly focused on these one or two governing aspects of the problem. At later stages, they could refine their model and only at this stage could include less important aspects.

- Test the answer. Mathematical modelling can be a lengthy trial and error process. Participants therefore defined some simple examples on which they could test their mathematical solution. This was difficult but proved to be a vital step in the building of valid models. Since the questions treated during the workshop referred to real world problems, every time they produced a model, participants had to answer the two following questions:

- Was the answer expected?

- Did the result make sense?

Should 'no' be one of the answers, the model had to be revised to correct the error. Otherwise, further refinements could be envisaged. In all cases, students were not able to reach a positive outcome at the end of the process. Although this was felt as disappointing at first, a analysis of the results and the model pinpointed where things went wrong and lead to interesting conclusions anyway.

Producing one's first model is a momentous task. With guidance provided by their teachers and the MACSI researchers, during the session, all groups were able to produce a rudimentary model. The work initiated in the second session was continued in homework sessions for nearly three months. Participants were also given the opportunity to informally present their models and/or express their concerns to the MACSI people during a third plenary session before completing their work in homework sessions.

\subsection{Third plenary session: presenting the results}

Communication has become a major aspect of scientific research in the few decades. Being able to present a group's work in a clear and concise manner is a valuable skill. Basic rules to present its work were introduced during the third plenary session. Workshop participants were therefore asked to present their results in two forms.

- Poster presentation. A poster presentation is a good alternative to a fully written report: it allowed students and educators to keep a trace of the work that could stand 
time and could be easily be viewed by numerous people. Producing a poster also forced the students to efficiently summarise their work in and present it in an attractive fashion. For many participants, this was a first time experience that they will have repeat many times during their academic and professional life.

- Oral presentation. Public speaking is most feared by a lot of people, see for example [24, 25, 26]. Designing and delivering effective presentations is a difficult skill to master [27, 28]. For this reason, workshop participants were asked to prepare for a short 8 to 10 minute presentation to be given in public (mainly their peers). As is standard in conferences, they were to expect a short question and answer session after their presentation.

Participants prepared their poster and presentation during 3 to 4 weeks under the supervision of their teacher. To conclude the project, all participants were invited for an afternoon presentation session in the University of Limerick, opened to all. This gave most students their first opportunity to be the (scientific) centre of attention and perform in front of a significant audience.

\section{Sample students results}

In this section some of the models formulated for the three problems investigated during the workshop are reported. In the authors' experience, participants very often come up with original ideas that have never been investigated before: should the same questions be asked again, participants would certainly not proceed to the same answers. Here are some examples of what was achieved during the project.

\subsection{Marathon}

Participants were given the following indications:

- You could look for various marathon results and do some statistics.

- You could also consider the quantity of up- and down-hills in the course.

- You could evaluate the time it takes you to run a shorter distance and extrapolate the results.

- The amount of training you will be doing could also be taken into account.

Participants decided to use another approach. Although they were too young to run a marathon, they decided to use the sports facilities in their school to run shorter distances, $400 \mathrm{~m}$ and $1500 \mathrm{~m}$. Using similar data they found for world records on the web, they derived the following formula

$$
Z=\frac{42 X Y}{10800 Y-1440 X}
$$


where $X, Y$ denote the times needed to run $1500 \mathrm{~m}$ and $400 \mathrm{~m}$ in seconds and $Z$ is the time needed to run the marathon in hours. This formula estimates the speed of the runner during the marathon from the speeds during the $1500 \mathrm{~m}$ and $400 \mathrm{~m}$ speeds. The students estimated this speed and tuned the constants in the formula using their own running times.

\subsection{Facebook and Twitter}

Participants were given the following indications:

- You could try to identify the differences between networks like Twitter and Facebook

- You could consider examples with a reduced number of people.

- You could also study the number of followers or any other relevant data.

Students decided to focus on twitter and suggested three formulae of the popularity $P$

$$
P_{1}=\frac{A}{T} \quad P_{2}=\frac{A}{B T} \quad P_{3}=\frac{A}{B T^{2}}
$$

where $A$ in the number of followers, $B$ denotes the number of tweets and indicates the user's activity and $T$ represents the time on Twitter. Students then went on to test these formulas on famous people they were familiar with and studied the differences in their rankings.

\subsection{Iceberg}

Participants were given the following indications:

- You may want to study the energy necessary to melt an iceberg and the latent heat of fusion.

- You could consider the variation of ambient temperature in your model.

- You could also study the time it would take to tow an iceberg to Saudi Arabia.

Most groups decided to use these suggestions and started by investigating feasibility: they considered the size of the iceberg, the capabilities of towing boats, the distance to travel and the cost of this operation. Then, they went on to carry out experiments in the lab to estimate the melting time of an ice cube and tried to extend their results to an iceberg by decomposing the iceberg into small volumes with a size similar to the ice cubes they studied before.

In all three examples, students developed models that can appear overly simple at first sight. However, students had to test their results and through this they got a deeper understanding of the concepts they have used which will have much longer lasting effect. This was shown in particular by the feed-back which will now be presented. 


\section{Feedback}

\section{$5.1 \quad$ Students' perspective}

At the end of their project, participants were asked to fill in a feedback sheet. Questions asked concerned the format of the workshop and its content. When the total number of answers exceeds the number of participants (35), some students have given more than one answer.

1. Did you enjoy the project?

\begin{tabular}{lccc}
\hline Year & $4^{\text {th }}$ & $5^{\text {th }}$ & Total \\
\hline Yes & 12 & 20 & $\mathbf{3 2}$ \\
No & 0 & 3 & $\mathbf{3}$ \\
\hline
\end{tabular}

2. Did you find the project stimulating?

\begin{tabular}{lccc}
\hline Year & $4^{t h}$ & $5^{\text {th }}$ & Total \\
\hline Yes & 12 & 21 & $\mathbf{3 3}$ \\
No & 0 & 2 & $\mathbf{2}$ \\
\hline
\end{tabular}

3. Did you find the work you did

\begin{tabular}{lccc}
\hline Year & $4^{\text {th }}$ & $5^{\text {th }}$ & Total \\
\hline Too easy & 0 & 1 & $\mathbf{1}$ \\
Right level & 10 & 20 & $\mathbf{3 0}$ \\
Too difficult & 2 & 5 & $\mathbf{7}$ \\
\hline
\end{tabular}

4. Did you enjoy the group work?

\begin{tabular}{lccc}
\hline Year & $4^{\text {th }}$ & $5^{\text {th }}$ & Total \\
\hline Yes & 12 & 20 & $\mathbf{3 2}$ \\
No & 0 & 2 & $\mathbf{2}$ \\
\hline
\end{tabular}

Participants were asked to comment further and made the following points. They underlined the positive aspects of group work: it created positive dynamics, allowed for more opinions to be expressed, more fruitful discussions that led to success. It also divided the amount of work and made the task easier but also more challenging and gratifying. They also underlined in their comments how it allowed them to socialise more within the group and enjoy the project. People who did not enjoy group work pointed out that they found it difficult to organise meetings with the other members of their group and could not get involved as much as they would have liked. 
5. Do you feel you completed the project successfully?

\begin{tabular}{lccc}
\hline Year & $4^{\text {th }}$ & $5^{\text {th }}$ & Total \\
\hline Yes & 12 & 12 & $\mathbf{2 4}$ \\
No & 0 & 11 & $\mathbf{1 1}$ \\
\hline
\end{tabular}

Commenting on this question, whatever their answer, most participants underlined that they learned a lot. Most of the people who answered 'no' pointed out that they did not believe their results and some wished they had had more time to continue their work.

6. What did you learn during this project?

Participants first mentioned skills : mathematical modelling, how you can simplify a complex problem into several simpler ones, how to produce and model, how people can create formulas and use them or the importance of checking and analysing one's results. They also pointed out that during the workshop, they learned about mathematics, its wide range of application and how it can be used to solve complex problems.

7. What did you enjoy in this project?

Group work and the challenge of a new approach were the most popular answers. Participants also enjoyed the creativity and the 'out of the box' thinking that were requested from them. The sense of accomplishment and independence were cited as well.

8. What did you dislike in this project?

Although a quarter of participants answered 'nothing', the time necessary to complete the project was mentioned by a few as were the difficulty to start the model from scratch and the frustration of failing.

9. What did you find most challenging about the project?

Starting the model from scratch and tuning the equations so the results made sense were cited by nearly all participants.

10. What did you find least interesting about the project?

Although most participants did not mention anything here, each part of the project was mentioned a few times.

11. Did the project change your perception of mathematics?

\begin{tabular}{lccc}
\hline Year & $4^{\text {th }}$ & $5^{\text {th }}$ & Total \\
\hline Yes, positively & 12 & 19 & $\mathbf{3 1}$ \\
Yes, negatively & 0 & 0 & $\mathbf{0}$ \\
No & 0 & 4 & $\mathbf{4}$ \\
\hline
\end{tabular}


On the positive side, in their comments, participants underlined that they discovered real world applications of mathematics and realised there is more to mathematics that they had seen before. They also commented that they found this first experience of mathematical modelling rewarding. This project acted as an eye-opener: participants pointed out that although sometimes very complex, mathematics can be interesting and allow to express one's creativity. One person who answered 'no' pointed out that he already had a very good opinion of mathematics which is why his opinion did not change.

Overall, this project proved a very positive experience for the students: there is no significant difference between the two levels involved. They thoroughly enjoyed the work, found it stimulating and adapted to their knowledge of mathematics. Fourth and fifth year students gave very similar answers to all questions apart from number 5; this exception is more related to the subject choice than the age. This project was very challenging for participants as they had to mix scientific abilities and creativity. This was very much perceived as a new out of the box way of dealing with mathematics. Although most did enjoy each aspect of the work, some found parts more difficult, less interesting and more challenging. However, most got the impression they learned a lot during the course of the project and developed useful skills. Finally, this project improved the perception of mathematics among students as it showed them new and enjoyable applications and unexpected uses.

\subsection{Teacher's perspective}

\subsubsection{Origin}

The aim of this project was to challenge very capable students by exposing them to problems which would require application of science and maths already learned at secondary school to real world problems. These problems didn't obviously lend themselves to mathematical analysis so would require a significant shift in the mindset of the students involved. The project grew from a discussion between the Headmaster and physics teacher in Clongowes Wood College about the possibility of introducing more activities to challenge high achieving students. The physics teacher contacted Prof. James Gleeson in the University of Limerick to seek advice and support. Prof. Gleeson was immediately enthusiastic and supportive and was instrumental in setting up the project and creating the link between MACSI and Clongowes Wood College.

\subsubsection{Selection}

The Physics teacher offered the project to everyone in the fifth year honours physics class and to all students in Transition Year. Twenty three fifth years and twelve fourth years signed up. It was made very clear that the project was voluntary and would involve a commitment to meeting once a week for an hour and a quarter, working independently outside these sessions and attending workshops with University of Limerick teachers. Some students were concerned about the workload and their ability to cope with the level of the material. The top students in physics and maths applied. No one was rejected. 


\subsubsection{Process}

The University of Limerick led workshops in the College were excellent. They stimulated the students but did not provide specific answers. It was very clear that these would be student models and that all models would most likely be different. It was also very clear that there would be no single right answer. This was an entirely new concept which it took many students some time to accept. Questions were answered with questions and guidance was very subtle. Students found this approach challenging and often frustrating as they were continually forced to develop their own models and strategies but ultimately all saw its benefit and understood and appreciated the methodology.

Following the workshops the groups met every Thursday night from 8 to $9.30 \mathrm{pm}$ with the Physics teacher. During this time students conducted their own supervised experiments in the laboratory, discussed their personal work with the group and with the teacher and decided on ways to progress. This proved to be an excellent educational model as very quickly the groups began distributing tasks amongst themselves and dividing up responsibilities. Everyone brought their own research and ideas to the group and all opinions were listened to and considered. It was interesting to observe the high level of cooperation and team work develop within the groups.

The announcement that a power point and poster presentation would be made in the University of Limerick really added another level to the project. Groups were now under pressure to finish their models and prepare their final presentation.

\subsubsection{Achievement}

The project was successful in many different ways. First, it challenged all of the students intellectually and stretched their thinking and understanding in exactly the way that had been desired. Second, it allowed students the opportunity to interact with researchers at the cutting edge of this type of work. Third, it provided students with a genuine insight into how maths and physics works in the real world and that there can be many correct answers to a single problem. Fourth, it changed many students perception of maths and physics positively and has stimulated real interest in some in pursuing careers in these areas. Fifth, students found the project genuinely enjoyable.

The collaboration within groups was very successful with general sharing of and respect for ideas and opinions. Students often looked forward eagerly to the evening sessions to discuss new ideas. The distribution of roles within groups and the acceptance of responsibility for a particular area of research was another success with all participants feeling valued and valuable.

The final presentation added another dimension of communicating results of scientific research. The quality of posters and power point presentations was extremely high and was taken very seriously by all. Presentations are encouraged within the College science faculty and it was excellent for the students to realise that this is the way research is actually presented in the real world. Students were nervous before making these presentations in the University but all felt very positive and affirmed afterwards about the experience. 


\subsubsection{Personally}

The physics teacher in Clongowes found the link with the University researchers to be both stimulating and energising. The work of guiding the groups in the evenings and discussing new ideas with them was a most enjoyable and rewarding experience. The project was very satisfying as it achieved its objective in challenging and stimulating very capable students. It also proved very satisfying in its development of deeper understanding of real world maths and physics for students and in the development of curiosity about careers in these areas.

\section{Conclusion}

The collaboration between Clongowes Wood College and MACSI proved extremely successful. A workshop format based on the study group model and university taught modules was defined to encourage participants to discover mathematical modelling and the links between all STEM components. Participants took part in four working sessions spread over six months animated by their teacher and MACSI researchers. They worked on the project 90 minutes every week under the supervision of their teacher. Participants developed in groups models on simple problems with open-ended answers. Every group produced a mathematical model and made a critical analysis of their results. Overall, participants enjoyed the experience very much and feed back from both students and teachers was very positive. Essential features for a successful workshop were

- The nature of the problems to be modelled,

- The involvement of MACSI researchers and the close collaboration with the Physics teacher,

- The length of the project which allowed participants to organise their work and reflect on their achievements,

- Alternating plenary and homework sessions.

The workshop significantly improved the perception of mathematics among participants. This underlines the importance of similar activities and should encourage participants to pursue a career involving STEM subjects.

\section{Acknowledgments}

The authors would like to thank the authorities of Clongowes Wood College, Ireland, for their constant support during the project. They are also very grateful to Professor John O'Donoghue and Professor James Gleeson (University of Limerick) for their support, encouragements and helpful comments.

S.O'Hara and the authorities of Clongowes Wood College would like to thank Professor James Gleeson, Dr. Jean Charpin and Dr. Martina O'Sullivan for setting up this project and 
for their constant support throughout. They are also very grateful to the University of Limerick and the Mathematics Applications Consortium for Science and Industry for their support.

J.P.F. Charpin and D. Mackey acknowledge the support of the Mathematics Applications Consortium for Science and Industry (www.macsi.ul.ie) funded by the Science Foundation Ireland Mathematics Initiative grant 06/MI/005.

\section{References}

[1] D.N. Hunt and D.A. Lawson. Trends in mathematical competency of a-level students on entry to university. Teaching Mathematics and its Applications, 15 (4-9):167-173, 1996.

[2] D. Thompson K. Crowther and C. Cullingford. Engineering degree students are deficient in mathematical expertise- why? International Journal of Mathematical Education in Science and Technology, 28(6):785-792, 1997.

[3] P.K. Armstrong and A.C. Croft. Identifying the learning needs in mathematics of entrants to undergraduate engineering programmes in an english university. European Journal of Engineering Education, 24(1):59-71, 1999.

[4] J. Barry and S. Davis. Essential mathematical skills for undergraduate students (in applied mathematics, science and engineering). International Journal of Mathematical Education in Science and Technology, 30(4):499-512, 1999.

[5] E. De Carrera. Mathematics education at the university: an item difficult to enter on. In 9th International Congress on Mathematical Education (ICME 9), Tokyo, Japan, 2000. http://www.stolaf.edu/people/steen/Projects/WGA/decarrera.html. Last time accessed 24 July 2012.

[6] J. Evensky, D. Kao, Q. Yang, R. Fadele, and R. Fenner. Addressing prerequisite mathematical needs- a case study in introductory economics. International Journal of Mathematical Education in Science and Technology, 28(5):629-639, 1997.

[7] O. Gill. What counts as service mathematics? An investigation into the 'mathematical problem 'in Ireland. PhD thesis, University of Limerick, Ireland, 2006.

[8] J. O’Donoghue. An intervention to assist at risk students in service mathematics courses at the university of limerick: University of limerick teaching fellowship scheme. Technical report, University of Limerick, Ireland, 1999.

[9] Project Maths. http://www.projectmaths.ie. Last time accessed 24 July 2012.

[10] John Thomasian, Black Point Policy Solutions, LLC. Building a Science, Technology, Engineering and Maths education agenda. An update of state actions, 2011. National Governors Association, USA. http://www.nga.org/files/live/sites/NGA/files/pdf/1112STEMGUIDE.PDF. Last time accessed 24 July 2012. 
[11] H. Cormican (Chair, STEM Review). Report of the STEM review, 2009. Department of Education, Department of Employment and Learning, Northern Ireland, UK. http://www.deni.gov.uk/report_of_the_stem_2009_review.pdf. Last time accessed 24 July 2012.

[12] Towards a 10-year plan for science, technology, engineering and mathematics (STEM) education and skills in Queensland, discussion paper, 2007. Department of Education, Training and the Arts, Queensland, Australia. http://education.qld.gov.au/projects/stemplan/docs/stem-discussion-paper.pdf. Last time accessed: 24 July 2012.

[13] Science week Ireland. http://www.scienceweek.ie/index.asp. Last time accessed 24 July 2012.

[14] Engineers week Ireland. http://www.engineersweek.ie/. Last tiem accessed 24 July 2012.

[15] Maths week Ireland. http://www.mathsweek.ie. Last time accessed 24 July 2012.

[16] BT young scientist \& technology exhibition. http://www.btyoungscientist.com/. Last time accessed 24 July 2012.

[17] J.P.F. Charpin, P. Hanrahan, J.F. Mason, S.B.G. O'Brien, and M. O'Sullivan. The macsi summer school: a case study in outreach in mathematics. International Journal of Mathematical Education in Science and Technology, page DOI:10.1080/0020739X.2012.662293, 2012.

[18] J. P. F. Charpin and S.B.G. OBrien. Improving the industrial/mathematics interface. In A. Arajo, A. Fernandes, A. Azevedo, and J.-F. Rodrigues, editors, EIMI 2010 Conference educational interfaces between mathematics and industry, pages 145-155, April 2010.

[19] Clongowes Wood College S.J.. http://www.clongowes.net. Last time accessed 24 July 2012.

[20] Physical Sciences Olympiad. http://www.dcu.ie/olympiads/physics.html. Last time accessed 24 July 2012.

[21] Academic ranking of world universities - 2011, Shanghai Ranking Consultancy, 2011. http://www.shanghairanking.com/ARWU2011.html. Last time accessed: 25 May 2012.

[22] Times higher education world university rankings 2011-12, Times Higher Education, 2012. http://www.timeshighereducation.co.uk/world-university-rankings/20112012/reputation-rankings.html. Last time accessed: 24 July 2012.

[23] QS world university rankings, QS Topuniversities, 2012. http://www.topuniversities.com/university-rankings/world-university-rankings/2011. Last time accessed: 24 July 2012. 
[24] Top 10 worst fears of people, Power 95-9 radio, 2011. http://power959.com/top-10-worstfears-of-people/. Last time accessed 24 July 2012.

[25] List of worst fears, MyTopDozen website, 2010. http://www.mytopdozen.com/Worst_Fears.html. Last time accessed: 25 May 2012.

[26] M.B. Stein, J.R Walker, and D.R. Forde. Public-speaking fears in a community sample: Prevalence, impact on functioning, and diagnostic classification. Archives of General Psychiatry, 53(2):169-174, 1996.

[27] J. P. Hafler. Effective presentations: tips for success. Nature Immunology, 12(11):1021$1023,2011$.

[28] J. Winn. Avoiding death by powerpoint. Journal of Professional Issues in Engineering Education and Practice, 129(3):115-118, 2003. 